\title{
Composição química e energética de alimentos de origem vegetal determinada em aves de diferentes idades
}

\author{
Arele Arlindo Calderano ${ }^{1}$, Paulo Cezar Gomes ${ }^{2}$, Luiz Fernando Teixeira Albino², Horacio \\ Santiago Rostagno ${ }^{2}$, Renata Mara de Souza ${ }^{1}$, Heloisa Helena de Carvalho Mello ${ }^{1}$
}

${ }^{1}$ Doutorando em Zootecnia, UFV, Viçosa, MG.
2 Departamento de Zootecnia, UFV, Viçosa, MG

RESUMO - Foram realizados quatro ensaios para determinar a energia metabolizável aparente (EMA) e a energia metabolizável aparente corrigida pelo balanço de nitrogênio (EMAn) de dez alimentos de origem vegetal para aves em diversas idades. Os alimentos estudados foram: farelo de soja 45\%, farelo de soja 48\%, soja integral extrusada, soja integral desativada, soja integral micronizada, farinha de soja desativada, concentrado proteico de soja, farelo de glúten de milho $21 \%$, gérmen de milho e quirera de arroz. Utilizou-se o método de coleta total de excretas, em delineamento experimental inteiramente casualizado, com 11 tratamentos e 6 repetições nos quatro ensaios. No primeiro, segundo e terceiro ensaios, foram utilizados frangos de corte com 10 a 17; 26 a 33; e 40 a 47 dias de idade, respectivamente, e no quarto ensaio galos com 25 semanas de idade. Os valores de EMAn ( $\mathrm{kcal} / \mathrm{kg})$, na matéria natural, determinados no primeiro, segundo, terceiro e quarto ensaios foram, respectivamente: $2.069,2.148,2.272$ e 2.231 para o farelo de soja $45 \%$; 2.214, $2.225,2319$ e 2.247 para o farelo de soja $48 \% ; 3.322,3.331,3.405$ e 3.493 para a soja integral extrusada; 3.016, 3.067, 3.139 e 3.388 para a soja integral desativada; $3.557,3.638,3.828$ e 3.869 para a soja integral micronizada; 2.292, 2.348, 2.518 e 2.502 para a farinha de soja desativada; 2.356, 2.399, 2.509 e 2.486 para o concentrado proteico de soja; 1.826, 1.882, 2.110 e 1.942 para o farelo de glúten de milho $21 \% ; 2.605,2.764,2.925$ e 2.832 para o gérmen de milho; e 2.967, 3.029, 3.096 e 3.026 para a quirera de arroz.

Palavras-chave: coleta total, frangos de corte, galos

\section{Chemical and energetic composition of feedstuffs of plant origin for poultry at different ages}

\begin{abstract}
Four assays were carried out to determine the apparent metabolizable energy (AME) and nitrogen corrected apparent metabolizable energy (AMEn) of ten feedstuffs of vegetable origin for poultry at different ages. The chemical composition of the ten feedstuffs was also determined: 45\% soybean meal, $48 \%$ soybean meal, extruded full-fat soybean, deactivated full-fat soybean, micronized full-fat soybean, deactivated soybean meal, soybean protein concentrate, corn gluten meal $21 \%$, corn germ and broken rice. The method of total excreta collection was used and a randomized complete experimental design was used with 11 treatments and six replications, in the four assays. In the $1^{\text {st }}, 2^{\text {nd }}$ and $3^{\text {rd }}$ assays broiler chicks were used aged 10 to 17,26 to 33 and 40 to 47 days, respectively, and in the $4^{\text {th }}$ assay roosters were used with 25 weeks of age. The AMEn values (as-fed basis) determined in the $1^{\text {st }}, 2^{\text {nd }}, 3^{\text {rd }}$ and $4^{\text {th }}$ assay were, respectively: 2069, 2148,2272 and 2231 for $45 \%$ soybean meal; 2214, 2225, 2319 and 2247 for $48 \%$ soybean meal; 3322, 3331, 3405 and 3493 for extruded full-fat soybean; 3016, 3067, 3139 and 3388 for deactivated full-fat soybean; 3557, 3638, 3828 and 3869 for micronized full-fat soybean; 2292, 2348, 2518 and 2502 for deactivated soybean meal; 2356, 2399, 2509 and 2486 for soybean protein concentrate; 1826, 1882, 2110 and 1942 for corn gluten meal 21\%; 2605, 2764, 2925 and 2832 for corn germ; and 2967,
\end{abstract} 3029, 3096 and 3026 for broken rice.

Key Words: broiler chicks, roosters, total collection

\section{Introdução}

A formulação de rações se dá pela combinação de vários alimentos de forma a atender corretamente as exigências nutricionais dos animais. No Brasil existem vários alimentos alternativos ao milho e farelo de soja que podem ser utilizados na alimentação das aves. No entanto, conhecer os valores de composição química e energética desses alimentos é importante para que sejam desenvolvidos programas de alimentação eficientes a custos mínimos.

Os valores energéticos dos alimentos têm sido normalmente expressos na forma de energia metabolizável 
e um dos fatores que podem interferir na sua determinação é a idade das aves utilizadas nos ensaios de metabolismo. De acordo com Brumano et al. (2006), com o avanço da idade e a maturidade do sistema digestível, as aves alcançam maior capacidade de digerir e absorver os nutrientes, apresentando melhor digestibilidade da energia.

Os valores de composição química e energética dos alimentos podem ser obtidos em tabelas disponíveis na literatura nacional (Embrapa, 1991; Rostagno et al., 2005). Assim, o uso dessas tabelas tem sido importante para formulação de dietas mais eficientes e para o desenvolvimento da avicultura brasileira. No entanto, são necessárias pesquisas para que essas exigências sejam constantemente atualizadas e as informações disponíveis aos nutricionistas mais precisas.

Objetivou-se com este trabalho determinar a composição química e os valores de energia metabolizável aparente e aparente corrigida pelo balanço de nitrogênio de alguns alimentos de origem vegetal para aves em diferentes idades.

\section{Material e Métodos}

Foram realizados quatro ensaios de metabolismo no Setor de Avicultura do Departamento de Zootecnia da Universidade Federal de Viçosa (UFV), no período de novembro de 2006 a fevereiro de 2007. Os ensaios foram realizados com frangos de corte com 10 a 17, 26 a 33 e 40 a 47 dias de idade e galos com 25 semanas de idade.

Os alimentos estudados foram: farelo de soja $45 \%$, farelo de soja $48 \%$, soja integral extrusada, soja integral desativada, soja integral micronizada, farinha de soja desativada, concentrado proteico de soja, farelo de glúten de milho $21 \%$, gérmen de milho e quirera de arroz.

Para determinação da composição química e energética dos alimentos, foram realizadas análises de matéria seca (MS), energia bruta (EB), proteína bruta (PB), extrato etéreo (EE), fibra bruta (FB), fibra em detergente neutro (FDN), fibra em detergente ácido (FDA), matéria mineral (MM), cálcio $(\mathrm{Ca})$ e fósforo $(\mathrm{P})$ no Laboratório de Nutrição Animal do Departamento de Zootecnia da UFV, segundo métodos descritos por Silva \& Queiroz (2002).

Os valores de energia metabolizável aparente (EMA) e energia metabolizável aparente corrigida pelo balanço de nitrogênio (EMAn) dos alimentos foram determinados pelo método tradicional de coleta total de excretas. O período experimental em cada ensaio teve duração de oito dias: três dias de adaptação às rações experimentais e às baterias e cinco dias de coleta total de excretas.
No primeiro ensaio, foram utilizados 528 pintos de corte machos da linhagem Cobb com 10 dias de idade e peso médio de $239 \mathrm{~g}$, distribuídos em delineamento inteiramente casualizado, com 11 tratamentos, 6 repetições e 8 aves por unidade experimental. As aves foram criadas em círculos de proteção em galpão de alvenaria e receberam ração inicial formulada de acordo com recomendações de Rostagno et al. (2005) até 10 dias de idade.

No segundo ensaio, foram utilizados 396 frangos de corte machos da linhagem Cobb com 26 dias de idade e peso médio de $1.130 \mathrm{~g}$, distribuídos em delineamento inteiramente casualizado, com 11 tratamentos, 6 repetições e 6 aves por unidade experimental. As aves receberam ração inicial e de crescimento, formuladas segundo Rostagno et al. (2005), até os 26 dias de idade.

No terceiro ensaio, foram utilizados 198 frangos de corte machos da linhagem Cobb com 40 dias de idade e peso médio de $2.318 \mathrm{~g}$, distribuídos em delineamento inteiramente casualizado, com 11 tratamentos, 6 repetições e 3 aves por unidade experimental. As aves receberam ração inicial e de crescimento, formulada segundo Rostagno et al. (2005), até os 40 dias de idade.

No quarto ensaio, foram utilizados 132 galos Leghorn, com peso médio de $2.172 \mathrm{~g}$, distribuídos em delineamento inteiramente casualizado, com 11 tratamentos, 6 repetições e 2 aves por unidade experimental. As aves foram criadas em piso até 25 semanas de idade recebendo ração para cada fase, segundo Rostagno et al. (2005).

Os tratamentos consistiram de uma ração-referência e dez rações-teste, cada uma com um dos alimentos-teste em substituição a $30 \%$ da ração-referência. Foi utilizada uma ração-referência nos três primeiros ensaios (Tabela 1) e outra no quarto ensaio (Tabela 2).

As unidades experimentais foram constituídas de gaiolas metabólicas providas de bandejas metálicas cobertas com plástico. A coleta de excretas foi realizada duas vezes por dia, às $8 \mathrm{~h}$ e às $17 \mathrm{~h}$, e todo o material coletado foi acondicionado em sacos plásticos, que foram devidamente identificados e armazenados em congelador.

Ao final de cada ensaio, as excretas foram descongeladas, pesadas e homogeneizadas e uma amostra representativa foi retirada e colocada em estufa de ventilação forçada a $60{ }^{\circ} \mathrm{C}$ durante 72 horas para pré-secagem.

Foi contabilizada a quantidade total de ração consumida por unidade experimental durante o período de coletas em todos os quatro ensaios.

As análises de matéria seca, energia bruta e nitrogênio da ração-referência e das excretas foram realizadas no Laboratório de Nutrição Animal do Departamento de 
Tabela 1 - Composição percentual e calculada da ração-referência utilizada no primeiro, segundo e terceiro ensaios

\begin{tabular}{|c|c|}
\hline Ingrediente & $\%$ \\
\hline Milho & 61,49 \\
\hline Farelo de soja & 32,41 \\
\hline Óleo de soja & 1,93 \\
\hline Fosfato bicálcico & 1,85 \\
\hline Calcário & 0,91 \\
\hline Sal & 0,51 \\
\hline L-lisina $\mathrm{HCl}(98 \%)$ & 0,32 \\
\hline DL-metionina & 0,26 \\
\hline Premix vitamínico ${ }^{1}$ & 0,10 \\
\hline Cloreto de colina $60 \%$ & 0,10 \\
\hline Premix mineral ${ }^{2}$ & 0,05 \\
\hline Anticoccidiano (salinomicina $12 \%$ ) & 0,05 \\
\hline Avilamicina $10 \%$ & 0,01 \\
\hline Antioxidante (BHT) & 0,01 \\
\hline \multicolumn{2}{|l|}{ Composição calculada } \\
\hline Energia metabolizável (kcal/kg) & 3.000 \\
\hline Proteína bruta $(\%)$ & 20,00 \\
\hline Lisina digestível (\%) & 1,2 \\
\hline Metionina + Cistina digestível (\%) & 0,82 \\
\hline Treonina digestível (\%) & 0,67 \\
\hline Triptofano digestível (\%) & 0,22 \\
\hline Cálcio (\%) & 0,90 \\
\hline Fósforo disponível (\%) & 0,45 \\
\hline Sódio $(\%)$ & 0,22 \\
\hline \multicolumn{2}{|c|}{$\begin{array}{l}{ }^{1} \text { Composição por kg do produto: vit. A - } 12.000 .000 \mathrm{UI} \text {; vit. D3 - } 2.200 .000 \mathrm{UI} \text {; } \\
\text { vit. E - } 30.000 \mathrm{UI} \text {; vit. B1 - } 2.200 \mathrm{mg} \text {; vit. B2 - } 6.000 \mathrm{mg} \text {; vit. B6 - } 3.300 \mathrm{mg} \text {; } \\
\text { ácido pantotênico - } 13.000 \mathrm{mg} \text {; biotina - } 110 \mathrm{mg} \text {; vit. K3 }-2.500 \mathrm{mg} \text {; ácido } \\
\text { fólico - } 1.000 \mathrm{mg} \text {; ácido nicotínico - } 53.0000 \mathrm{mg} \text {; vit. B12 - } 16.000 \mu \mathrm{g} \text {; selênio } \\
\text { - } 0.25 \mathrm{~g} \text {; antioxidante }-120.000 \mathrm{mg} \text {; e veículo q.s.p. - } 1.000 \mathrm{~g} \text {. } \\
{ }^{2} \text { Composição por kg do produto: manganês - } 75.000 \mathrm{mg} \text {; ferro - } 20.000 \mathrm{mg} \text {; zinco - } \\
50.000 \mathrm{mg} \text {; cobre - } 4.000 \mathrm{mg} \text {; cobalto - } 200 \mathrm{mg} \text {; iodo - } 1.500 \mathrm{mg} \text { e veículo q.s.p. - } \\
1.000 \mathrm{~g}\end{array}$} \\
\hline
\end{tabular}

Zootecnia da UFV, segundo metodologia descrita por Silva \& Queiroz(2002).

As temperaturas máxima e mínima no interior do galpão (Tabela 3) foram mensuradas diariamente em todos os ensaios. Os valores de EMA e de EMAn foram calculados por meio das equações descritas por Matterson et al. (1965).

As análises estatísticas foram processadas por meio do programa SAEG (Sistema para Análises Estatísticas - UFV, 2005). Foi realizada uma análise de variância conjunta dos dados e, para verificação dos possíveis efeitos das diferentes idades sobre os valores de EMA e EMAn, fixando os tratamentos, foi utilizado o teste de Student NewmanKeuls a $5 \%$ de probabilidade, independentemente de a interação ser significativa.

Tabela 3 - Valores médios de temperatura máxima e mínima registradas no galpão

\begin{tabular}{lcc}
\hline \multirow{2}{*}{ Ensaio } & \multicolumn{2}{c}{ Temperatura $\left({ }^{\circ} \mathrm{C}\right)$} \\
\cline { 2 - 3 } 10 a 17 dias & $27,8 \pm 1,1$ & Mínima \\
26 a 33 dias & $28,4 \pm 2,1$ & $22,7 \pm 1,1$ \\
40 a 47 dias & $28,5 \pm 1,3$ & $22,0 \pm 2,4$ \\
Galos & $27,0 \pm 1,6$ & $21,8 \pm 1,3$ \\
\hline
\end{tabular}

Tabela 2 - Composição percentual e calculada da ração-referência utilizada no quarto ensaio

\begin{tabular}{lc}
\hline Ingrediente & $\%$ \\
\hline Milho & 81,34 \\
Farelo de soja & 15,12 \\
Fosfato bicálcico & 1,39 \\
Calcário & 0,46 \\
L-lisina HCl (98\%) & 0,43 \\
Sal & 0,41 \\
DL-metionina & 0,24 \\
L-treonina & 0,20 \\
L-triptofano & 0,10 \\
Premix vitamínico ${ }^{1}$ & 0,10 \\
Cloreto de colina 60\% & 0,10 \\
Premix mineral ${ }^{2}$ & 0,05 \\
Anticoccidiano (salinomicina 12\%) & 0,05 \\
Antioxidante (BHT) & 0,01 \\
Composição calculada & \\
Energia metabolizável (kcal/kg) & 2.750 \\
Proteína bruta (\%) & 14,03 \\
Lisina digestível (\%) & 0,50 \\
Metionina + cistina digestível (\%) & 0,50 \\
Treonina digestível (\%) & 0,40 \\
Triptofano digestível (\%) & 0,15 \\
Cálcio (\%) & 0,60 \\
Fósforo disponível (\%) & 0,35 \\
Sódio (\%) & 0,20 \\
\hline Conpoco & \\
\hline
\end{tabular}

${ }^{1}$ Composição por kg do produto: vit. A - 12.000.000 UI; vit. D3 - 2.200.000 UI; vit. E - 30.000 UI; vit. B1 - $2.200 \mathrm{mg}$; vit. B2 - $6.000 \mathrm{mg}$; vit. B6 - $3.300 \mathrm{mg}$; ácido pantotênico - $13.000 \mathrm{mg}$; biotina - $110 \mathrm{mg}$; vit. K3 $-2.500 \mathrm{mg}$; ácido fólico $-1.000 \mathrm{mg}$; ácido nicotínico $-53.0000 \mathrm{mg}$; vit. B12 - $16.000 \mu \mathrm{g}$; selênio $-0,25 \mathrm{~g}$; antioxidante $-120.000 \mathrm{mg}$; e veículo q.s.p. $-1.000 \mathrm{~g}$.

${ }^{2}$ Composição por kg do produto: manganês - $75.000 \mathrm{mg}$; ferro $-20.000 \mathrm{mg}$; zinco $50.000 \mathrm{mg}$; cobre - $4.000 \mathrm{mg}$; cobalto - $200 \mathrm{mg}$; iodo $-1.500 \mathrm{mg}$ e veículo q.s.p. $1.000 \mathrm{~g}$

\section{Resultados e Discussão}

O teor de PB dos farelos de soja esteve dentro dos padrões de mercado (Tabela 4). Em geral, as composições química e energética dos farelos de soja apresentaram poucas variações em relação às tabelas de Rostagno et al. (2005) e da Embrapa (1991). O farelo de soja 48\% apresentou menor teor de FB e FDN em comparação ao farelo de soja 45\%. Esses dados confirmam afirmativa de Ost et al. (2005) de que maiores teores de fibra são encontrados nos farelos de soja com menor teor de $\mathrm{PB}$, que possuem maior quantidade de casca.

Ocorreu variação entre a composição química e energética das sojas integrais extrusada, desativada e micronizada, o que provavelmente foi devido aos diferentes processamentos a que foram submetidas. Para a soja extrusada, o valor de EE foi inferior aos citados por Café et al. (2000) e Freitas et al (2005), que encontraram 19,55\% e 19,36\%, respectivamente. A composição química da soja desativada apresentou algumas variações em relação à descrita por Freitas et al. (2005), principalmente quanto aos teores de PB e EE. Na soja micronizada, destacou-se 
o valor de FDN, que foi inferior ao citado por Rostagno et al. (2005), de 29,31\%, mas semelhante ao citado por Zonta et al. (2004) $(12,73 \%)$.

A composição química e energética da farinha de soja desativada foi semelhante à da farinha de soja de alta proteína estudada por Nery et al. (2007), exceto quanto aos valores de FDN e FDA, que foram 26,58 e 25,44\%, respectivamente.

A composição química do concentrado proteico de soja apresentou variações em relação àquela citada por Rostagno et al. (2005) e Brumano et al. (2006). Essas variações possivelmente foram ocasionadas pelos métodos utilizados na extração da parte solúvel nãoproteica dos flocos de soja desengordurados durante o processo de produção do concentrado proteico de soja.

O farelo de glúten de milho apresentou composição química e energética semelhante à citada por Rodrigues et al. (2001), exceto para o teor de PB, que foi de $24 \%$. O valor de FDN do gérmen de milho foi superior aos citados por Nagata et al. (2004) e Rostagno etal. (2005), de 18,50 e 26,22\%.

Em geral, as composições química e energética da quirera de arroz variaram em relação aos valores obtidos por Rostagno et al. (2005) e Generoso et al. (2008). Essa variação provavelmente ocorreu pelas diferenças na qualidade da quirera avaliada, pois, de acordo com Brum Jr. et al. (2007), a quirera de arroz pode ser encontrada em graus variados de limpeza e seus principais contaminantes são casca de arroz, sementes de capim-arroz (Equinocloa spp) e angiquinho (Aeschinomene spp).

As variações nos valores de composição química e energética dos alimentos, em relação à literatura, podem ser decorrentes de vários fatores, como as diferenças nas condições de cultivo e de solo, de clima e de cultivares, além das possíveis diferenças nos processamentos a que são submetidos.

Os valores de energia metabolizável aparente foram em média 8,$84 ; 8,38$ e 7,72\% maiores que os valores de
EMAn no primeiro, segundo e terceiro ensaios, respectivamente (Tabela 5). No quarto ensaio, essa diferença foi em média de 3,77\%. Soares et al. (2005), trabalhando com frangos na fase pré-inicial, observaram que os valores de EMA foram $8,6 \%$ maiores para alimentos de origem vegetal. Essa diferença caracteriza um balanço de nitrogênio positivo, ou seja, houve retenção de nitrogênio pelas aves em todos os ensaios. De acordo com Nunes at al. (2001), é normal que os valores de EMA, quando determinados pelo método tradicional com pintos sejam superiores aos de EMAn, caracterizando a retenção de nitrogênio dos animais em crescimento.

Aves mais velhas apresentaram valores de EMA e EMAn maiores $(\mathrm{P}<0,05)$ para soja integral desativada, soja integral micronizada, farelo de glúten de milho $21 \%$ e gérmen de milho. Para o farelo de soja $45 \%$ e a farinha de soja desativada, apenas os valores de EMAn foram maiores $(\mathrm{P}<0,05)$ nas aves mais velhas. Estes resultados estão de acordo com aqueles citados por Batal \& Parsons (2002), que verificaram aumento da EMAn de dietas à base de milho e de farelo de soja para frangos a partir da segunda semana de vida. Esses autores relataram que o aumento no valor de EMAn com a maior idade das aves é ocasionado pela melhora no aproveitamento dos nutrientes dos alimentos. Segundo Soares et al. (2005), os pintos nas primeiras semanas de vida ainda não estão completamente desenvolvidos fisiologicamente. Dessa forma, apresentam menor capacidade de produção de enzimas e secreções gástricas e pior digestibilidade dos nutrientes em relação às aves mais velhas. De acordo com Sakomura et al. (2004), a atividade das enzimas amilase, tripsina e lipase aumenta com o avanço da idade das aves e a fase de maior aumento de atividade é entre a $1^{\underline{a}}$ e $2^{\underline{a}}$ semanas de idade. No entanto, a maioria das tabelas de composição química e energética dos alimentos apresenta apenas valor de EMAn para cada alimento e esse valor é utilizado para a formulação de dietas para aves em todas as idades. Dessa forma, como as aves

Tabela 4 - Composição química e energética dos alimentos, expressa na matéria natural

\begin{tabular}{|c|c|c|c|c|c|c|c|c|c|c|}
\hline Alimento & $\begin{array}{l}\text { Matéria } \\
\text { seca }(\%)\end{array}$ & $\begin{array}{l}\text { Proteína } \\
\text { bruta }(\%)\end{array}$ & $\begin{array}{c}\text { Extrato } \\
\text { etéreo }(\%)\end{array}$ & $\begin{array}{c}\text { Matéria } \\
\text { mineral }(\%)\end{array}$ & $\begin{array}{l}\text { Cálcio } \\
(\%)\end{array}$ & $\begin{array}{c}\text { Fósforo } \\
(\%)\end{array}$ & $\begin{array}{c}\text { Fibra } \\
\text { bruta }(\%)\end{array}$ & $\begin{array}{c}\text { Fibra em } \\
\text { detergente } \\
\text { neutro }(\%)\end{array}$ & $\begin{array}{c}\text { Fibra em } \\
\text { detergente } \\
\text { ácido }(\%)\end{array}$ & $\begin{array}{c}\text { Energia } \\
\text { bruta } \\
(\mathrm{kcal} / \mathrm{kg})\end{array}$ \\
\hline Farelo de soja $45 \%$ & 89,54 & 45,61 & 1,91 & 5,56 & 0,23 & 0,55 & 5,71 & 13,75 & 7,19 & 4154 \\
\hline Farelo de soja $48 \%$ & 89,25 & 48,14 & 1,46 & 6,02 & 0,30 & 0,60 & 4,64 & 10,25 & 8,07 & 4164 \\
\hline Soja integral extrusada & 93,95 & 37,07 & 17,67 & 4,41 & 0,21 & 0,45 & 7,72 & 16,76 & 10,67 & 5139 \\
\hline Soja integral desativada & 90,67 & 36,24 & 18,69 & 4,48 & 0,21 & 0,43 & 9,89 & 26,01 & 18,51 & 5182 \\
\hline Soja integral micronizada & 93,83 & 39,28 & 21,72 & 4,60 & 0,17 & 0,50 & 1,46 & 11,70 & 5,46 & 5348 \\
\hline Farinha de soja desativada & 93,00 & 50,39 & 0,97 & 6,16 & 0,23 & 0,53 & 1,76 & 9,23 & 5,43 & 4254 \\
\hline Concentrado proteico de soja & 90,79 & 63,42 & 0,50 & 5,74 & 0,27 & 0,76 & 4,82 & 15,82 & 3,15 & 4327 \\
\hline Farelo de glúten de milho $21 \%$ & 90,66 & 19,54 & 2,96 & 4,63 & 0,04 & 0,62 & 8,44 & 38,26 & 11,81 & 4042 \\
\hline Gérmen de milho & 90,05 & 10,39 & 12,09 & 2,74 & 0,04 & 0,43 & 6,42 & 38,01 & 8,35 & 4407 \\
\hline Quirera de arroz & 88,01 & 6,77 & 0,62 & 0,65 & 0,03 & 0,19 & 0,46 & 7,65 & 2,09 & 3660 \\
\hline
\end{tabular}


tendem a apresentar melhor aproveitamento da energia dos alimentos com o avanço da idade, o conteúdo energético das rações pode ficar superestimado para aves em fase inicial ou subestimado para aves na fase final.

Houve aumento significativo $(\mathrm{P}<0,05)$ nos valores de EMAn do farelo de soja $45 \%$ com o aumento da idade das aves. Segundo Mello et al. (2009), a presença de alguns oligossacarídeos e fatores antinutricionais nesse alimento podem prejudicar a utilização dos nutrientes pelas aves, principalmente nas primeiras semanas de idade. Entretanto, não houve diferença estatística $(\mathrm{P}>0,05)$ nos valores de EMAn do farelo de soja $48 \%$ entre as fases estudadas. Em geral, os valores de EMAn dos farelos de soja foram similares àqueles citados por Bellaver et al. (2004) e Rostagno et al. (2005).

Não foi observada diferença estatística $(\mathrm{P}>0,05)$ nos valores de EMA e EMAn da soja integral extrusada obtidos nos quatro ensaios. Diferentes valores de EMAn para esse alimento foram obtidos por Freitas et al. (2005) com galos adultos $(3560 \mathrm{kcal} / \mathrm{kg})$ e com pintos de corte $(3.266 \mathrm{kcal} / \mathrm{kg})$.

$\mathrm{O}$ maior valor $(\mathrm{P}<0,05)$ de EMAn da soja integral desativada foi obtido com galos adultos. De maneira similar, Freitas et al. (2005) encontraram diferença entre os valores de EMAn da soja integral desativada determinados com pintos de 12 a 21 dias de idade $(2971 \mathrm{kcal} / \mathrm{kg})$ e galos adultos (3.172 kcal $/ \mathrm{kg})$, embora esses resultados tenham sido inferiores aos obtidos neste trabalho.
Em relação à soja integral micronizada, os valores de EMA e EMAn obtidos com aves mais velhas e com galos foram maiores $(\mathrm{P}<0,05)$. Os valores de EMAn obtidos nos quatro ensaios foram inferiores a $4.025 \mathrm{kcal} / \mathrm{kg}$, valor obtido por Zonta et al. (2004) em frangos de 24 a 26 dias de idade. No entanto, o valor obtido com frangos de 26 a 33 dias neste trabalho foi semelhante àquele citado por Rostagno et al. (2005) (3.660 kcal/ kg). Entre as sojas integrais, a soja micronizada foi a que apresentou os maiores valores de EMAn, provavelmente em virtude do tipo de processamento, que pode afetar os níveis de EE e FB de um alimento e influenciar diretamente no conteúdo de energia metabolizável (Nascimento et al., 1998).

Os maiores valores $(\mathrm{P}<0,05)$ de EMAn da farinha de soja desativada foram obtidos em frangos de 40 a 47 dias e em galos, contudo não diferiram significativamente do valor obtido com aves de 26 a 33 dias de idade. Os valores de EMAn da farinha de soja desativada obtidos nos quatro ensaios foram superiores ao encontrado por Nery et al. (2007) $(1.984 \mathrm{kcal} / \mathrm{kg})$ em frangos de 21 a 31 dias de idade.

Não foram observadas diferenças significativas entre os valores de EMA e EMAn do concentrado proteico de soja obtidos nos quatro ensaios realizados. Brumano et al. (2006) não observaram diferença nos valores de EMAn do concentrado proteico de soja para frangos de corte de 21 a 30 dias de idade $(2.043 \mathrm{kcal} / \mathrm{kg})$ e de 41 a 50 dias de idade $(2.155 \mathrm{kcal} / \mathrm{kg})$. Os valores obtidos nos quatro ensaios

Tabela 5 - Valores de energia metabolizável aparente (EMA) e aparente corrigida (EMAn), expressos na matéria natural

\begin{tabular}{|c|c|c|c|c|}
\hline \multirow[t]{2}{*}{ Alimento } & \multicolumn{4}{|c|}{ EMA (kcal/kg) } \\
\hline & 10 a 17 dias & 26 a 33 dias & 40 a 47 dias & Galos \\
\hline Farelo de soja $45 \%$ & $2288 \mathrm{a}$ & $2393 a$ & $2500 \mathrm{a}$ & $2347 a$ \\
\hline Farelo de soja $48 \%$ & $2477 \mathrm{a}$ & $2496 a$ & $2553 \mathrm{a}$ & $2355 \mathrm{a}$ \\
\hline Soja integral extrusada & $3563 a$ & $3578 \mathrm{a}$ & $3634 a$ & $3593 a$ \\
\hline Soja integral desativada & $3232 \mathrm{a}$ & $3282 \mathrm{ab}$ & $3340 \mathrm{ab}$ & $3474 b$ \\
\hline Soja integral micronizada & $3829 a$ & $3930 \mathrm{ab}$ & $4113 b$ & $4045 \mathrm{ab}$ \\
\hline Farinha de soja desativada & $2597 \mathrm{a}$ & $2655 \mathrm{a}$ & $2807 \mathrm{a}$ & $2633 a$ \\
\hline Concentrado proteico de soja & $2677 a$ & $2695 \mathrm{a}$ & $2838 \mathrm{a}$ & $2643 a$ \\
\hline Farelo de glúten de milho $21 \%$ & $1953 \mathrm{a}$ & $2016 a$ & $2243 b$ & $2011 \mathrm{a}$ \\
\hline Gérmen de milho & $2694 a$ & $2839 \mathrm{ab}$ & $2999 b$ & $2879 \mathrm{ab}$ \\
\hline Quirera de arroz & $3043 a$ & $3105 \mathrm{a}$ & $3192 \mathrm{a}$ & $3057 \mathrm{a}$ \\
\hline \multirow[t]{2}{*}{ Alimento } & \multicolumn{4}{|c|}{ EMAn (kcal/kg) } \\
\hline & 10 a 17 dias & 26 a 33 dias & 40 a 47 dias & Galos \\
\hline Farelo de soja $45 \%$ & $2069 a$ & $2148 \mathrm{ab}$ & $2272 b$ & $2231 \mathrm{ab}$ \\
\hline Farelo de soja $48 \%$ & $2214 a$ & $2225 \mathrm{a}$ & $2319 a$ & $2247 a$ \\
\hline Soja integral extrusada & $3322 \mathrm{a}$ & $3331 \mathrm{a}$ & $3405 \mathrm{a}$ & $3493 a$ \\
\hline Soja integral desativada & $3016 \mathrm{a}$ & $3067 a$ & $3139 a$ & $3388 b$ \\
\hline Soja integral micronizada & $3557 \mathrm{a}$ & $3638 \mathrm{a}$ & $3828 b$ & $3869 b$ \\
\hline Farinha de soja desativada & $2292 \mathrm{a}$ & $2348 \mathrm{ab}$ & $2518 b$ & $2502 \mathrm{~b}$ \\
\hline Concentrado proteico de soja & 2356 a & $2399 a$ & $2509 a$ & $2486 \mathrm{a}$ \\
\hline Farelo de glúten de milho $21 \%$ & $1826 \mathrm{a}$ & $1882 \mathrm{a}$ & $2110 \mathrm{~b}$ & $1942 \mathrm{a}$ \\
\hline Gérmen de milho & $2605 a$ & $2764 b$ & $2925 b$ & $2832 b$ \\
\hline Quirera de arroz & $2967 a$ & $3029 a$ & $3096 \mathrm{a}$ & $3026 a$ \\
\hline
\end{tabular}

Médias seguidas de letras diferentes na mesma linha diferem $(\mathrm{P}<0,05)$ entre si pelo teste Student Newman-Keuls. 
neste trabalho ficaram acima dos valores citados por Brumano et al. (2006) e foram inferiores àquele citado por Rostagno et al. (2005) $(2.677 \mathrm{kcal} / \mathrm{kg})$. As diferenças nos valores de EMA e EMAn entre os trabalhos podem estar relacionadas a variações na composição química do alimento.

O maior valor $(\mathrm{P}<0,05)$ de EMA e EMAn do farelo de glúten de milho foi obtido com frangos de 40 a 47 dias de idade. Os valores de EMAn obtidos nos quatro ensaios para esse alimento foram superiores ao de $1.796 \mathrm{kcal} / \mathrm{kg}$, citado por Rostagno et al. (2005).

Para o gérmen de milho, o valor de EMAn aumentou $(\mathrm{P}<0,05)$ a partir do segundo ensaio (26 a 33 dias). $\mathrm{O}$ alto valor de FDN observado nesse alimento pode ter prejudicado a digestibilidade de nutrientes como proteínas e gorduras, porém esse efeito pode ter sido mais evidente em aves de 10 a 17 dias de idade. Os valores de EMAn encontrados para esse alimento foram inferiores aos citados por Rodrigues et al. (2001), Nagata et al. (2004) e Rostagno et al. (2005). Essa diferença pode ser explicada pelos maiores valores de FB e FDN obtidos neste trabalho em relação aos citados por esses autores.

Os valores de EMAn obtidos para a quirera de arroz foram menores que aqueles citados por Generoso et al. (2008) em pesquisa com frangos de corte de 21 a 30 dias de idade $(3.138 \mathrm{kcal} / \mathrm{kg})$ e de 41 a 50 dias de idade $(3.278 \mathrm{kcal} / \mathrm{kg})$ e por Rostagno et al. (2005) (3.315 kcal/kg). Diferenças na granulometria da quirera de arroz podem ser responsáveis por essa variação, pois a redução no tamanho das partículas pode favorecer o processo de digestão.

\section{Conclusões}

A variação dos valores de energia metabolizável aparente e aparente corrigida pelo balanço de nitrogênio obtidos para os alimentos com aves em diferentes idades comprova que a utilização de um único valor de energia metabolizável para todas as fases de criação pode levar à superestimativa dos valores, principalmente para aves nas primeiras semanas de idade.

\section{Referências}

BATAL, A.B.; PARSONS, C.M. Effects of age on nutrient digestibility in chicks fed different diets. Poultry Science, v. 81, p.400-407, 2002.

BELLAVER, C.; ZANOTTO, D.L.; GUIDONI, A.L. Metabolizable energy and amino acids relationships with the soluble fractions of protein and fiber of vegetable feed ingredients. Revista Brasileira de Zootecnia, v.33, n.6, p.2274-2282, 2004.

BRUM JR., B.S.; ZANELLA, I.; TOLEDO, G.S.P. et al. Dieta para frangos de corte contendo quirera de arroz. Ciência Rural, v.37, n.5, p.1423-1429, 2007.
BRUMANO, G.; GOMES, P.C.; ALBINO, L.F.T. et al. Composição química e valores de energia metabolizável de alimentos protéicos determinados com frangos de corte em diferentes idades. Revista Brasileira de Zootecnia, v.35, n.6, p.2297-2302, 2006.

CAFÉ, M.B.; SAKOMURA, N.K.; JUNQUEIRA, O.M. et al. Determinação do valor nutricional das sojas integrais processadas para aves. Revista Brasileira de Ciência Avicola, v.2, n.1, p.67-74, 2000 .

EMPRESA BRASILEIRA DE PESQUISA AGROPECUÁRIA EMBRAPA. Centro Nacional de Pesquisa de Suínos e Aves CNPSA. Tabelas de composição química e valores energéticos de alimentos para suínos e aves. 3.ed. Concórdia: EMBRAPA-CNPSA, 1991. 97p. (Documento 19).

FREITAS, E.R.; SAKOMURA, N.K.; NEME, R. et al. Efeito do processamento da soja integral sobre a energia metabolizável e a digestibilidade dos aminoácidos para aves. Revista Brasileira de Zootecnia, v.34, n.6, p.1938-1949, 2005.

GENEROSO, R.A.R.; GOMES, P.C.; ROSTAGNO, H.S. et al Composição química e energética de alguns alimentos para frangos de corte em duas idades. Revista Brasileira de Zootecnia, v.37, n.7, p.1251-1256, 2008

MATTERSON, L.S.; POTTER, L.M.; STUTZ, M.W. et al. The metabolizable energy of feed ingredients for chickens. Storrs: University of Connecticut (Agricultural Experiment Station Research Report), 1965. v.11, 11p.

MELLO, H.H.C.; GOMES, P.C.; ROSTAGNO, H.S. at al. Valores de energia metabolizável de alguns alimentos obtidos com aves de diferentes idades. Revista Brasileira de Zootecnia, v.38, n.5, p.863-868, 2009.

NAGATA, A.K.; RODRIGUES, P.B.; FREITAS, R.T.F. et al. Energia metabolizável de alguns alimentos energéticos para frangos de corte, determinada por ensaios metabólicos e por equações de predição. Ciências e Agrotecnologia, v.28, n.3, p.668-677, 2004.

NASCIMENTO, A.H.; GOMES, P.C.; ALBINO, L.F.T. et al. Valores de composição química e energética de alimentos para frangos de corte. Revista Brasileira de Zootecnia, v.27, n.3, p.579-583, 1998.

NERY, L.R.; ALBINO, L.F.T.; ROSTAGNO, H.S. et al. Valores de energia metabolizável de alimentos determinados com frangos de corte. Revista Brasileira de Zootecnia, v.36, n.5, p.1354-1358, 2007.

NUNES, R.V.; ROSTAGNO, H.S.; ALBINO, L.F.T. et al. Composição bromatológica, energia metabolizável e equações de predição da energia do grão e de subprodutos do trigo para pintos de corte. Revista Brasileira de Zootecnia, v.30, n.4, p.785-793, 2001

OST, P.R.; RODRIGUES, P.B.; FIALHO, E.T. et al. Valores energéticos de sojas integrais e de farelos de soja, determinados com galos adultos e por equações de predição. Ciências e Agrotecnologia, v.29, n.2, p.467-475, 2005

RODRIGUES, P.B.; ROSTAGNO, H.S.; ALBINO, L.F.T. et al. Valores energéticos do milheto, do milho e subprodutos do milho, determinados com frangos de corte e galos adultos. Revista Brasileira de Zootecnia, v.30, n.6, p.1767-1778, 2001.

ROSTAGNO, H.S.; ALBINO, L.F.T.; DONZELE, J.L. et al. Tabelas brasileiras para aves e suínos: composição de alimentos e exigências nutricionais. Viçosa, MG: Universidade Federal de Viçosa, 2005. 186p.

SAKOMURA, N.K.; BIANCHI, M.D.; PIZAURO JR., J.M. et al Efeito da idade dos frangos de corte na atividade enzimática e digestibilidade dos nutrientes do farelo de soja e soja integral Revista Brasileira de Zootecnia, v.33, n.4, p.924-935, 2004.

SILVA, D.J.; QUEIROZ, A.C. Análise de alimentos: métodos químicos e biológicos. 3.ed. Viçosa, MG: UFV/Imprensa Univiversitária, 2002. 235p.

SOARES, K.R.; BERTECHINI, A.G.; FASSANI, E.J. et al. Valores de energia metabolizável de alimentos para pintos de corte na fase pré-inicial. Ciência e Agrotecnologia, v.29, n.1, p.238-244, 2005 . 
UNIVERSIDADE FEDERAL DE VICOSA- UFV. Central de Processamento de Dados - UFV/CPD. SAEG - Sistema para análises estatísticas. Versão 9.1. Viçosa, MG, 2005. $301 \mathrm{p}$.
ZONTA, M.C.M.; RODRIGUES, P.B.; ZONTA, A. et al. Energia metabolizável de ingredientes protéicos determinada pelo método de coleta total e por equações de predição. Ciências e Agrotecnologia, v.28, n.6, p.1400-1407, 2004. 